\section{Metal stent migration after chemotherapy}

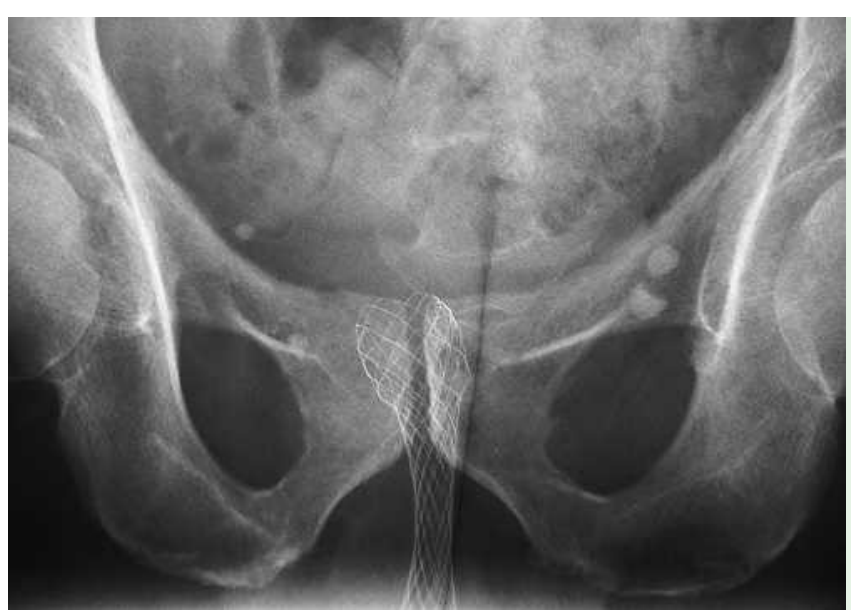

Figure 1 Abdominal radiograph showing migration of the selfexpandable metallic stent across the anal sphincter.

Self-expandable metal stents (SEMS) have been widely used to relieve malignant obstruction of the upper and lower gastrointestinal tract $[1,2]$. There is now a considerable body of experience reported in the literature on colonic stent insertion for the treatment of malignant disease, both as a palliative measure and as a "bridge to surgery" [3]. There are several potential complications associated with stent insertion, however. A pooled analysis of the use of SEMS for the palliation of malignant colorectal obstruction showed that colonic stent migration occurred in $11.8 \%$ of cases [4], though SEMS are only very rarely expelled right through the anal sphincter. We report a case of SEMS migration following chemotherapy, with subsequent expulsion of the SEMS across the anal sphincter and manual removal.

In November 2005, a 67-year-old man with a history of colonic adenocarcinoma (at the splenic flexure) underwent SEMS insertion across the malignant stricture after developing intestinal subocclusion symptoms. After SEMS placement the patient was treated with chemotherapy. In

\section{References}

1 Spinelli P, Cerrai FG, Dal Fante M et al. Endoscopic treatment of upper gastrointestinal tract malignancies. Endoscopy 1993; 25: $675-678$

2 Camunez F, Echenagusia A, Simo A et al. Malignant colorectal obstruction treated by means of self-expanding metallic stents: effectiveness before surgery and in palliation. Radiology 2000; 216: 492 - 497

3 Mainar A, Gregorioariza MA, Tejero E et al. Acute colorectal obstruction: treatment with self-expandable metallic stents before scheduled surgery - results of a multicenter study. Radiology 1999; 210: 65-69

4 Sebastian S, Johnston S, Geoghegan $T$ et al. Pooled analysis of the efficacy and safety of self-expanding metal stenting in malignant colorectal obstruction. Am J Gastroenterol 2005; 100: $1203-1204$

\section{Bibliography}

DOI 10.1055/s-2007-966155

Endoscopy 2007; 39: E111

(c) Georg Thieme Verlag KG Stuttgart · New York . ISSN 0013-726X

\section{Corresponding author}

\section{B. Mangiavillano, MD}

Division of Gastroenterology and Gastrointestinal Endoscopy

University Vita-Salute San Raffaele

Scientific Institute San Raffaele

Via Olgettina 62

20132 Milan

Italy

Fax: +39-02-26432504

mangiavillano.benedetto@hsr.it 